\title{
KAJIAN STANDAR NASIONAL PENDIDIKAN SMA BATIK 1 SURAKARTA
}

\author{
Dynna Sri Wulandari ${ }^{1}$, Baskoro Adi Priyatno2, Maridi ${ }^{3}$ \\ 1,2,3 Universitas Sebelas Maret, Surakarta, 57126, Indonesia \\ Email : ${ }^{1}$ ds.wulandari@student.uns.ac.id
}

Diajukan: 5 January 2020; Diterima: 27 February 2020; Diterbitkan: 30 April 2020

\begin{abstract}
Abstrak: Setiap warga Negara Republik Indonesia berhak memperoleh pendidikan yang bermutu untuk mencapai tujuan pendidikan nasional. Untuk mencapai pendidikan yang bermutu, maka ditetapkan Standar Nasional Pendidikan (SNP). Tujuan penelitian ini untuk mengkaji Standar Nasional Pendidikan di SMA Batik 1 Surakarta. Penelitian ini merupakan penelitian kualitatif dan kuantitatif. Data diperoleh dengan wawancara. Hasil penelitian terdapat temuan gap pada standar isi sebesar 1,42\%, standar proses sebesar 2,36\%, standar kelulusan sebesar $1,42 \%$, standar pendidik dan tenaga kependidikan sebesar $0,94 \%$, standar sarana dan prasarana sebesar 4,72\%, standar pengelolaan sebesar $0 \%$, standar pembiyaan sebesar 0,94\%, dan standar penilaian sebesar 3,77\%.
\end{abstract}

Kata kunci: SNP, Kualitatif, Kuantitatif

Abstract: Every citizen of the Republic of Indonesia has the right to obtain quality education to achieve national education goals. To achieve quality education, the National Education Standards (SNP) are set. The purpose of this study was to examine the National Education Standards at SMA Batik 1 Surakarta. This research is a qualitative and quantitative research. Data obtained by interview. The results of the study found a gap in content standards of $1.42 \%$, process standards of $2.36 \%$, graduation standards of $1.42 \%$, standards of educators and education personnel at $0.94 \%$, facilities and infrastructure standards of $4.72 \%$, the management standard is $0 \%$, the financing standard is $0.94 \%$, and the valuation standard is $3.77 \%$.

Keywords: SNP, Qualitative, Quantitative

\section{Pendahuluan}

Setiap warga Negara Republik Indonesia berhak memperoleh pendidikan yang bermutu. Untuk itulah setiap sekolah (penyelenggara pendidikan) wajib menjamin mutu pendidikan. Agar terjaga mutu pendidikan, maka disusunlah Standar Nasional Pendidikan (SNP).sehingga dapat dikatakan bahwa SNP sebagai acuan mutu pendidikan (Peraturan Pemerintah no.32 tahun 2013).

Peraturan Pemerintah nomor 32 tahun 2013 lebih lanjut menjelaskan bahwa SNP digunakan untuk mengembangkan kurikulum. Hal ini dilakukan guna mencapai tujuan pendidikan nasional, yaitu mencerdaskan kehidupan bangsa yang memiliki keimanan dan ketaqwaan pada Tuhan Yang Maha Esa, bangsa yang memiliki akhlak mulia, sehat, terampil, bermartabat, kreatif dan innovative (Undangundang RI no.20 tahun 2003).

Standar Nasional Pendidikan menengah mencakup 8 standar, yaitu kompetensi lulusan, isi, proses, sarana dan prasarana, pendidik dan tenaga kependidikan,pembiayaan, pengelolaan, dan penilaian. Standar kompetensi lulusan sebagai dasar penyusunan standar isi, standar proses, standar penilaian, standar pendidik dan tenaga kependidikan, standar pengelolaan, standar sarana dan prasarana serta standar pembiayaan.

Standar Nasional Pendidikan sabagai acuan mutu pendidikan, maka dalam hal ini sekolah melakukan kontrol mutu (quality control), jaminan mutu (quality assurance) dan mutu terpadu (total quality). Menurut Aokland (1996) dalam Fitra dkk. (2018) mengatakan bahwa mutu adalah adanya keunggulan produk atau jasa. Macdonald (1996) dalam Fitra dkk. (2018) mengatakan bahwa mutu adanya kesesuaian antara produk dengan persyaratannya. Untuk menjaga mutu, maka perlu diadakan kontrol mutu, yaitu kegiatan pendeteksian dan pengeliminasian produkproduk gagal, yaitu produk-produk yang tidak sesuai dengan persyaratannya atau standar (PusatPenjaminan Mutu Pendidikan, 2012), lebih lanjut menjelaskan bahwa control mutu dengan dilaksanakannya ujian sumatif, ujian akhir, ujian sekolah.

Fitra dkk. (2018) peningkatan mutu memerlukan perencanaan (plan) dan komitmen 
pada pencapaian visi, misi dan tujuan. Menurut Fitra, dkk. (2018), bahwaPenjaminan mutu meliputi penetapan dan pemenuhan standar manajemen mutu, sehingga kepuasan stakeholder merupakan salah satu indikator keberhasilan mutu. Untuk mencapai hal itu perlu adanya pelaksanaan system penjaminan mutu internal. Menurut Penjaminan Mutu Pendidikan (2012), jaminan mutu merupakan usaha agar tidak dihasilkan produk cacat atau salah dari sejak awal proses. Dengan terlaksananya jaminan mutu, maka dapat menumbuhkan budaya mutu. Suatu budaya yang terus menerus menjaga produk yang bebas cacat. Menurut Indriasari dkk. (2018) hal ini dilakukan untuk mendapat kepercayaan masyarakat.

Agar kepercayaan meningkat maka pelu peningkatan kinerja yang spesialisasi jenis pekerjaannya dan adanya interaksi antar anggota. Dengan adanya spesialisasi maka dapat menghemat waktu, biaya tenaga dan pikiran. Handayani (2016) mengatakan bahwa, kemampuan guru dalam proses pendidikan sangat menentukan keberhasilan untuk mencapai tujuan penidikan. Karena guru menyusun rencana, melaksana rencanadan mengevaluasi kesesuaian antara hasil capaian dengan rencana.

Abdi dan Ananiah (2017) menambahkan bahwa untuk memunculkan keunggulan siswa dengan menerapkan model pembelajaran menyenangkan, inovatif dan kreatif serta sekolah menerapkan MBS (Manajemen Berbasis Sekolah). Untuk mencapai 8 Standar Nasional Pendidikan, skolah melibatkan komite dan stakeholder yang kompeten untuk mengembangkan sekolah.

Sehubungan dengan kontrol mutu, penjaminan mutu maka terciptalah budaya mutu (Penjaminan Mutu Pendidikan, 2012). SMA Batik 1 Surakarta adalah salah satu sekolah swasta yang berada dalam naungan Yayasan Pendidikan Batik. Sekolah ini mendapat kepercayaan masyarakat yang ditunjukkan dengan jumlah siswa sebanyak 1234 siswa. Sekolah ini berusaha untuk meningkatkan mutu.

Sehubungan dengan hal itu, peneliti melakukan kajian delapan Standar Nasional Pendidikan di sekolah ini. Tujuan penelitian ini adalah untuk mengkaji Standar Nasional Pendidikan SMA Batik 1 Surakarta.

\section{Metode Penelitian}

Metode penelitian adalah penelitian kualitatif dan kuantitatif. Data diperoleh dengan wawancara tentang pemenuhan Standar Nasional Pendidikan di SMA Batik 1 Surakarta pada pejabat yang berwenang dan guru. Data yang terkumpul dikonversi, sehingga diperoleh data kuantitatif.

\section{Hasil Penelitian dan Pembahasan}

Peningkatan mutu lembaga pendidikan dapat dilihat dari pemenuhan SNP yang terdiri atas 8 standar. Data penelitian diperoleh dengan pengisian instrumen Standar Nasional Pendidikan. Penilaian ini pada 8 standar, yaitu isi, proses, 3) standar kompetesi lulusan, 4) standar pendidik dan tenaga kependidikan, 5) standar sarana dan prasarana, 6) standar pengelolaan, 7) standar pembiayaan, dan 8) standar penilaian. Hasil observasi disajikan pada pada tabel 1 dan gambar 1 .

\begin{tabular}{lccc}
\multicolumn{4}{c}{ Tabel 1. Nilai SNP dan gap SNP } \\
\hline \multicolumn{1}{c}{ SNP } & $\begin{array}{c}\text { Data } \\
\text { Ideal }\end{array}$ & $\begin{array}{c}\text { Data } \\
\text { Real }\end{array}$ & $\begin{array}{c}\text { Gap data } \\
\text { ideal dengan } \\
\text { data real (\%) }\end{array}$ \\
\hline Standar Isi & 11.32 & 9.91 & 1.42 \\
\hline Standar Proses & 14.15 & 11.79 & 2.36 \\
\hline $\begin{array}{l}\text { Sandar } \\
\text { kelulusan }\end{array}$ & 16.98 & 15.57 & 1.42 \\
\hline $\begin{array}{l}\text { Standar } \\
\text { Pendidik dan } \\
\text { Tenaga } \\
\text { Kependidikan }\end{array}$ & 14.15 & 13.21 & \\
\hline $\begin{array}{l}\text { Standar Sarana } \\
\text { dan Prasaran }\end{array}$ & 15.57 & 10.85 & 4.72 \\
\hline $\begin{array}{l}\text { Standar } \\
\text { Pengelolaan }\end{array}$ & 5.66 & 5.66 & \\
\hline $\begin{array}{l}\text { Standar } \\
\text { pembiayaan }\end{array}$ & 4.25 & 3.30 & 0.94 \\
\hline $\begin{array}{l}\text { Standar } \\
\text { Penilaian }\end{array}$ & 17.92 & 14.15 & \\
\hline \begin{tabular}{l} 
TOTAL \\
\hline
\end{tabular} & 100 & 82.55 & 17.45 \\
\hline
\end{tabular}

Berdasarkan tabel 1 dan gambar 1 menunjukkan bahwa sekolah masih ada gap pada beberapa standar. Gap yaitu suatu kondisi adanya perbedaan antara kondisi standar dengan kondisi riil. Gap tersebut pada standar isi sebesar $1,42 \%$, standar proses sebesar $2,36 \%$, standar kelulusan sebesar $1,42 \%$, standar pendidik dan tenaga kependidikan sebesar $0,94 \%$, standar sarana dan prasarana sebesar $4,72 \%$, standar pengelolaan sebesar 
$0 \%$, standar pembiyaan sebesar $0,94 \%$, dan standar penilaian sebesar 3,77\%. Gap yang besar pada standar proses, standar sarana dan prasarana, serta standar penilaian. Gap standar proses sebesar 2,38\%. Gap standar sarana dan prasarana sebesar $4,72 \%$. Gap standar penilaian sebesar 3,77\%.

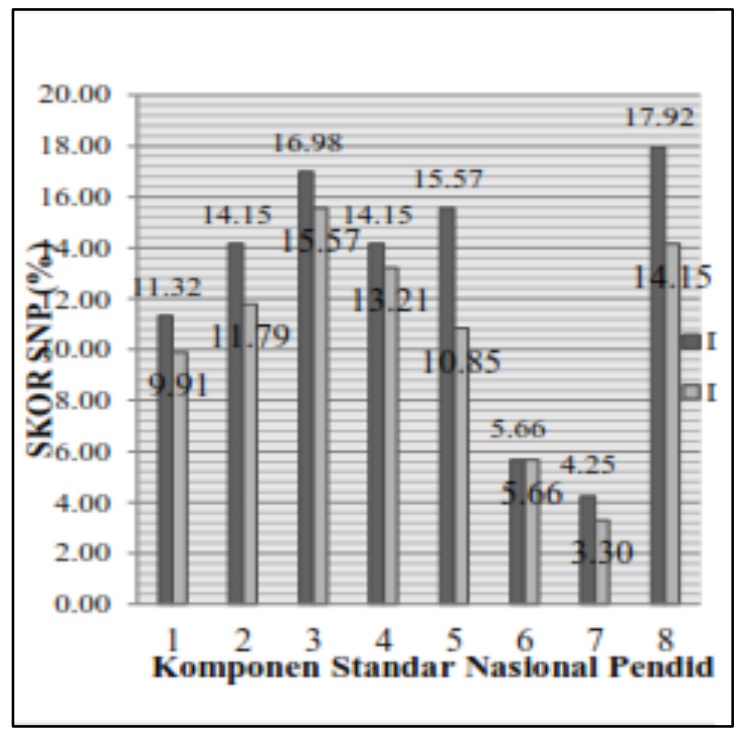

Gambar 1. Grafik penilaian data ideal dan data real SNP SMA Batik 1 Surakarta

Keterangan:

1. Standar Isi

2. Standar Proses

3. Standar Kelulusan

4. Standar Pendidik dan Tenaga

Kependidikan

5. Standar Sarana dan Prasarana

6. Standar Pengelolaan

7. Standar Pembiayaan

8. Standar Penilaian

Standar isi terdapat temuan bahwa sebagian silabus disusun oleh guru sendiri, penugasan terstruktur dan tidak terstruktur sebanyak 2-3 kali dalam sebulan dan KKM 75. Standar proses terdapat temuan bahwa guru menggunakan RPP yang sudah tersedia, guru melakukan remidiasi tes (bukan remedial teaching), guru menggunakan IT sebanyak 2-3 kali sebulan. Pada standar kelulusan terdapat temuan bahwa rata-rata siswa yang tuntas pada ulangan harian secara umum kurang dari $70 \%$. Standar pendidika dan tenaga kependidikan terdapat temuan ijazah kepala sekolah strata 2, guru hadir $80-100 \%$ karena adanya penugasan guru dari kepala sekolah. Pada standar sarana dan prasarana terdapat temuan bahwa luas ruang laboratorium kurang mencukupi jumlah siswa untuk satu kelas, ruang laboratorium mengalami alih fungsi, luas lahan kurang sesuai dengan jumlah siswa. Pada standar pembiayaan bahwa sekolah tidak membelajakan 100\% bahan atau alat habis pakai. Karena sebagian untuk perawatan alat-alat investaris, penggajian sebab tempat penelitian adalah sekolah swasta. Pada standar penilaian terdapat temuan bahwa kurang dari $50 \%$ guru menyusun soal tes tingkat C4-C6, kurang dari $50 \%$ guru mata pelajaran mengolah dan menganalisis hasil penilaian untuk mengetahui kemajuan dan kesulitan belajar, dan guru $<50 \%$ memberikan balikan hasil kerja siswa disertai masukan/komentar yang mendidik

\section{Kesimpulan dan Rekomendasi}

Berdasarkan data, maka dapat disimpulkan bahwa kajian SNP SMA Batik 1 Surakarta adalah: Gap tersebut pada standar isi sebesar $1,42 \%$, standar proses sebesar 2,36\%, standar kelulusan sebesar $1,42 \%$, standar pendidik dan tenaga kependidikan sebesar $0,94 \%$, standar sarana dan prasarana sebesar $4,72 \%$, standar pengelolaan sebesar $0 \%$, standar pembiayaan sebesar $0,94 \%$, dan standar penilaian sebesar $3,77 \%$.

Rekomendasi untuk memperbaiki dalam rangka pemenuhan SNP adalah: (1) Sebaiknya guru mengembangkan silabus dan RPP sendiri yang disesuaikan dengan kondisi sekolah. (2) Dalam pengembangan RPP ada kesesuaian antara kompetensi dasar, indikator pencapaian kompetensi, model pembelajaran, instrumen evaluasi. (3) Guru menyusun indikator pencapaian kompetensi sesuai kompetensi dasar. (4) Guru menggunakan model pembelajaran, media pembelajaran yang bervariatif, menyenangkan, menantang dan aktif. (5) Guru mengembangkan media pembelajaran yang sesuai dengan kompetensi dasar. (6) Guru mengembangkan instrumen penilaian yang secara bertahap mengacu pada C3-C6. (7) Guru melatihkan siswa untuk berpikir kritis dan penyelesaian masalah. (8) Perlu penyediaan ruang gudang. (9) Perlu perluasan ruang laboratoriumyang menampung seluru siswa dan sesuai standarnya. (10) Untuk pembelajaran yang sulit perlu diulang-ulang agar siswa paham. 


\section{Daftar Pustaka}

Fitra, Muh., Ruslan, Hendra. (2018). Urgensi Sistem Penjaminan Mutu Internal Terhadap Peningkatan Mutu Perguruan Tinggi. Jurnal Penjaminan Mutu vol. 4 no.1. hal 76-86

Indriasari, I., Setiawan, D.F., Nugraha, A.E.P. (2018), Integrasi Anggota Tim Kerja SMK Terakreitasi A dan C Dalam Memenuhi Standar Nasional Pendidikan, Jurnal Pendidikan Ekonomi UM Metro, Vol.6. No.2 (2018). hal. 39-47

Lampiran Peraturan Menteri Pendidikan dan Kebudayaan Republik Indonesia no. 21 tahun 2016 tentang Standar Isi Pendidikan dasar dan Menengah
Peraturan Pemerintah Republik Indonesia no.32 tahun 2013 tentang Perubahan Atas Peraturan Pemerintah nomor 19 tahun 2005 tentang Standar Nasional Pendidikan

Pusat Penjaminan Mutu Pendidikan. (2012). Pedoman Pemenuhan Standar Nasional Pendidikan Sekolah Menengah Atas/ Madrasah Aliyah. Badan Pengembangan Sumberdaya Manusia. Pendidikan dan Kebudayaan dan Penjaminan Mutu Pendidikan. Kementerian Pendidikan dan Kebudayaan

Undang-undang Republik Indonesia nomor 20 Tahun 2003 tentang Sistem Pendidikan Nasinal 